\title{
A validation study of crescents in predicting ESRD in patients with IgA nephropathy
}

Xiaoyan Zhang ${ }^{1 \dagger}$, Sufang Shi ${ }^{2 \dagger}$, Yan Ouyang ${ }^{1}$, Meng Yang ${ }^{1}$, Manman Shi ${ }^{1}$, Xiaoxia Pan ${ }^{1}$, Jicheng Lv ${ }^{2}$, Zhaohui Wang ${ }^{1}$, Hong Ren ${ }^{1}$, Pingyan Shen ${ }^{1}$, Weiming Wang ${ }^{1}$, Hong Zhang ${ }^{2}$, Jingyuan Xie ${ }^{1 *}$ and Nan Chen ${ }^{1 *}$

\begin{abstract}
Background: A working group on the Oxford classification of IgA nephropathy (IgAN) recently reported that crescents detected in kidney tissue predicted a worse renal outcome. However, this finding must be validated in independent cohorts before it can be widely applied to clinical practice.

Methods: Biopsy-proven IgAN patients were continuously recruited from two large renal centers in China from 1989 to 2014. All patients were followed for more than 1 year unless end stage renal disease (ESRD) occurred within 12 months. Crescents were defined as focal cellular or fibrocellular crescent formations. IgAN patients without detectable crescents were recruited to the CO group. Patients with crescents in less than or more than $1 / 4$ of all glomeruli were recruited to the $\mathrm{C} 1$ or $\mathrm{C} 2$ group, respectively. Primary outcome was defined as the time to ESRD, and the secondary outcome was defined as the time to an estimated glomerular filtration rate (eGFR) decline equal to or greater than $50 \%$ or to ESRD.
\end{abstract}

Results: In total, 1152 IgAN patients were recruited in this study. Among all patients, 53.7\% were in the C0 group, $38.8 \%$ were in the $\mathrm{C} 1$ group, and $7.5 \%$ were in the C2 group. Compared to patients in the C0 group, patients in the $\mathrm{C} 1$ or $\mathrm{C} 2$ group were younger, had more urinary protein excretion and lower eGFR, and presented with more severe mesangial hypercellularity, endocapillary proliferation or tubular atrophy/interstitial fibrosis. After 45 months of followup, ESRD had occurred in 80 (12.9\%), 46 (10.3\%) and 18 (20.9\%) of patients in the C0, C1 and C2 groups, respectively. By multivariable Cox regression analysis, inclusion in the $\mathrm{C} 1(\mathrm{HR}=1.07,95 \% \mathrm{Cl} 0.71-1.63), \mathrm{C} 2(\mathrm{HR}=0.84,95 \% \mathrm{Cl}$ $0.41-1.73)$, or $\mathrm{C} 1$ or $\mathrm{C} 2$ group ( $\mathrm{HR}=1.02,95 \% \mathrm{Cl}$ 0.68-1.52) was not associated with a higher rate of ESRD than inclusion in the CO group after adjusting for age, gender, eGFR, mean arterial pressure (MAP), MEST scores, and immunosuppressive treatment. However, in patients with nephrotic-range proteinuria, patients in either the C1 or C2 group had a higher rate of the primary outcome, ESRD ( $H R=2.54,95 \% \mathrm{Cl} 1.14-5.66)$ after adjusting for age, gender, eGFR, MAP, MEST scores, and immunosuppressive treatment. Similar results were found when we evaluated the association between crescents and the secondary outcome.

Conclusions: IgAN patients with crescents had more severe clinical and pathological manifestations than those without crescents. However, we failed to replicate the association between crescents and renal function progression in Chinese IgAN patients followed for more than 1 year.

Keywords: Crescent, IgA nephropathy (IgAN), Prognosis, End stage renal disease (ESRD)

\footnotetext{
*Correspondence: nephroxie@163.com; cnrj100@126.com

${ }^{\dagger}$ Xiaoyan Zhang and Sufang Shi contributed equally to this work

1 Department of Nephrology, Institute of Nephrology, Ruijin Hospital

Affiliated with Shanghai Jiao Tong University School of Medicine, 197

Ruijin Er Road, Shanghai 200025, China

Full list of author information is available at the end of the article
} 


\section{Background}

IgA nephropathy (IgAN) is the most common primary glomerulonephritis worldwide and is characterized by prominent IgA1 deposition in the glomerular mesangium $[1,2]$. The clinical course of IgAN and associated pathological lesions are highly variable [3-6]. Crescent formation is a common histopathological finding, occurring in approximately $20-50 \%$ of IgAN patients [7-11]. However, crescents were not effectively evaluated in the Oxford scoring system, the most widely accepted pathological classification of IgAN, nor in subsequent validation studies of the Oxford classification, including two large Chinese cohort studies [9, 12-14]. In addition, the value of crescents in predicting renal function progression in IgAN patients is inconsistent among patients of different ethnicities. Recently, crescents were reported to predict a worse renal outcome by an Oxford classification working group [15]. Based on 3096 IgAN patients from 16 countries across the world, crescents were found to be associated with a composite outcome including either ESRD or a $50 \%$ reduction in estimated glomerular filtration rate (eGFR) in patients not receiving immunosuppression. Furthermore, crescents in more than $1 / 4$ of glomeruli remained a predictor of poor outcomes in patients receiving immunosuppression. However, the inconsistency in the association between crescents and renal function deterioration among all cohorts in the study, for example, the Chinese cohort, suggested heterogeneity may exist among different populations. Therefore, the finding of this study needs to be validated in independent cohorts, especially in the Chinese population. In this study, we aim to evaluate the predictive value of crescents based on two extended Chinese IgAN cohorts.

\section{Methods}

\section{Study population and design}

We continuously recruited idiopathic IgAN patients from two extended renal centers in China (Department of Nephrology, Ruijin Hospital, affiliated with Shanghai Jiao Tong University School of Medicine; and Renal Division, Department of Medicine, Peking University First Hospital) between 1989 and 2014. The inclusion criteria were as follows: (1) Patients were diagnosed with primary IgAN by renal biopsy; (2) Patients were followed for more than 12 months unless ESRD occurred within 12 months; and (3) Patients did not have systemic diseases, such as systemic lupus erythematosus, Henoch-Schonlein purpura, or liver cirrhosis. Renal tissue slides were reviewed and scored by two experienced renal pathologists, and at least 8 glomeruli per slide were required for further review. A crescent was defined as an extracapillary lesion of any size containing more than two cell layers. A cellular crescent was indicated when more than $50 \%$ of the lesion was occupied by cells, and a fibrocellular crescent was defined as an extracapillary lesion comprising cells and extracellular matrix, with less than 50\% cells and less than $90 \%$ matrix. A fibrous crescent was defined as a lesion composed of more than $90 \%$ matrix covering the circumference of Bowman's capsule, and patients with these crescents were excluded from this study. Patients with crescents in $<1 / 4$ of all glomeruli were assigned to the $\mathrm{C} 1$ group. Patients with crescents in $\geq 1 / 4$ of all glomeruli were assigned to the $\mathrm{C} 2$ group, and patients without crescents were assigned to the $\mathrm{C} 0$ group. Baseline demographic and clinical data, including age, gender, mean arterial pressure (MAP), 24-h protein excretion and estimated glomerular filtration rate (eGFR) calculated by the CKD-EPI equation, were collected from all patients at the time of renal biopsy [16]. Nephrotic-range proteinuria was defined as 24-h urine protein $\geq 3.5 \mathrm{~g} / 24 \mathrm{~h}$. Hypertension was defined as systolic blood pressure $\geq 140 \mathrm{mmHg}(18.7 \mathrm{kPa})$ and/or diastolic blood pressure $\geq 90 \mathrm{mmHg}(12.0 \mathrm{kPa})$ or the use of antihypertensive agents at the time of renal biopsy. Immunosuppressive therapy was defined as treatment with corticosteroids and/or corticosteroid-sparing agents (including cyclophosphamide, azathioprine, mycophenolate, cyclosporine or tacrolimus). All biopsy specimens were processed routinely using standard light microscopy, immunofluorescence (IF) and electron microscopy (EM). For each biopsy specimen, the degrees of mesangial hypercellularity, endocapillary hypercellularity, segmental glomerulosclerosis and tubular atrophy/interstitial fibrosis were evaluated semi-quantitatively according to the Oxford Classification of IgAN. M1 was defined as a mesangial hypercellularity score higher than 0.5 , E1 was defined as the presence of endocapillary hypercellularity, S1 was defined as the presence of segmental glomerulosclerosis, T1 was defined as tubular atrophy/ interstitial fibrosis within $26-50 \%$ of the cortical area, and T2 was defined as tubular atrophy/interstitial fibrosis in greater than $50 \%$ of the cortical area. The primary outcome was the time to ESRD, defined as eGFR $<15 \mathrm{ml} /$ $\mathrm{min} / 1.73 \mathrm{~m}^{2}$ and the need for renal replacement therapy (dialysis or renal transplantation). The secondary outcome was the time to an eGFR decline of at least $50 \%$ or the time to ESRD, which was evaluable in 957 patients.

This study adhered to the principles of the Declaration of Helsinki II and was approved by the Institutional Review Board of Ruijin Hospital, Shanghai Jiao Tong University School of Medicine [Clinical Trial Ethics Committee Approval (2012-38)].

\section{Statistical analyses}

Categorical variables are presented as the number (percentage); quantitative variables were assessed for 
normality, and these data are presented as the mean \pm SD (or median and interquartile range for non-normally distributed variables). Normally distributed continuous data were compared across groups using the independent sample $t$ test or one-way ANOVA. Non-normally distributed continuous data were compared across groups using the Mann-Whitney U test or Kruskal-Wallis test. Categorical variables are presented as the frequency or percentage (\%), and proportions were compared using Pearson's $X^{2}$ test or Fisher's test as appropriate. Renal survival was measured from the time of biopsy and was analyzed using the Kaplan-Meier method, and the equality of survival functions was examined using the logrank test. Multivariate Cox regression analysis or linear regression was applied to identify independent factors associated with renal outcomes and eGFR slope $(\mathrm{P}<0.05$ indicated statistical significance). Statistical analyses were performed using SPSS (version 13.0).

\section{Results}

\section{Characteristics of validation patients}

We recruited a total of 1152 patients, of which 566 (49.1\%) were male, and the mean age was $35 \pm 12$ years. At the time of renal biopsy, patients had a urinary protein excretion of $1.4(0.7-2.6) \mathrm{g} / 24 \mathrm{~h}$ and an eGFR of $79.1(52.1-101.7) \mathrm{ml} / \mathrm{min} / 1.73 \mathrm{~m}^{2}$. The mean MAP was $95.8 \pm 13.5 \mathrm{mmHg}$, and $33.1 \%$ (381) of patients presented with hypertension. In total, $533(46.3 \%)$ patients had crescents in glomeruli. Of these patients, 447 (38.8\%) had crescents in less than $1 / 4$ of glomeruli (C1 group), and 86 (7.5\%) had crescents in more than $1 / 4$ of glomeruli $(\mathrm{C} 2$ group). Regarding MEST Oxford scores in all patients, $43.1 \%$ were $\mathrm{M} 1,42.1 \%$ were $\mathrm{E} 1,77.0 \%$ were $\mathrm{S} 1$, and $33.4 \%$ were $\mathrm{T} 1 / \mathrm{T} 2$. Compared to the $\mathrm{C} 0$ group, patients in the $\mathrm{C} 1$ and $\mathrm{C} 2$ groups were younger $(34.3 \pm 11.9$ years in $\mathrm{C} 1$ and $33.0 \pm 10.6$ years in $\mathrm{C} 2$ vs $36.5 \pm 12.1$ years in $\mathrm{C} 0$ ) and had higher levels of proteinuria [1.4 $(0.8-2.7) \mathrm{g} / 24 \mathrm{~h}$ in $\mathrm{C} 1$ and 2.5 (1.6-4.0) g/24 $\mathrm{h}$ in C2 vs $1.2(0.6-2.4) \mathrm{g} / 24 \mathrm{~h}$ in C0]. Patients in the $\mathrm{C} 2$ group had a lower eGFR than those in the C0 group [66.0 (47.1-92.0) vs 81.7 $(56.6-100.8) \mathrm{ml} / \mathrm{min} / 1.73 \mathrm{~m}^{2}$ ].

Compared to the $\mathrm{C} 0$ group, the $\mathrm{C} 1$ and $\mathrm{C} 2$ groups had more patients classified as M1 $(51.1 \%$ in $\mathrm{C} 1$ and $56.4 \%$ in $\mathrm{C} 2$ vs $35.5 \%$ in $\mathrm{C} 0$ ) and $\mathrm{E} 1$ (56.2\% in $\mathrm{C} 1$ and $80.8 \%$ in $\mathrm{C} 2$ vs $26.8 \%$ in $\mathrm{C} 0$ ). Meanwhile, there were more $\mathrm{S} 1$ patients in the $\mathrm{C} 1$ group than in the $\mathrm{C} 0$ group $(85.4 \%$ vs $72.0 \%$ ), and more $\mathrm{T} 1 / \mathrm{T} 2$ cases were found in the $\mathrm{C} 2$ group than in the C0 group (46.2\% vs $33.3 \%)$. Immunosuppressive agents, including corticosteroids with or without corticosteroid-sparing agents, were more commonly used in the $\mathrm{C} 2$ group than in the $\mathrm{C} 0$ group $(81.0 \%$ vs $49.8 \%$ ) (Table 1). Finally, among all recruited patients, the primary outcome of ESRD occurred in 144 individuals (12.5\%), and the secondary outcome occurred in 162 individuals (14.1\%).

\section{Crescent formation and renal outcomes}

Kaplan-Meier curves showed that patients in the $\mathrm{C} 0, \mathrm{C} 1$ and $\mathrm{C} 2$ groups had a similar mean primary outcome-free time $(176.3 \pm 7.5, \quad 225.4 \pm 14.8$ and $168.9 \pm 7.3$ months) and mean secondary outcome-free time $(163.7 \pm 7.8, \quad 188.9 \pm 18.3$ and

Table 1 Baseline cohort characteristics

\begin{tabular}{|c|c|c|c|c|}
\hline Variables & $\begin{array}{l}\text { Overall } \\
(n=1152)\end{array}$ & $\begin{array}{l}C 0 \\
(n=619)\end{array}$ & $\begin{array}{l}C 1 \\
(n=447)\end{array}$ & $\begin{array}{l}C 2 \\
(n=86)\end{array}$ \\
\hline Follow-up (months) & $45(25-70)$ & $45(24-70)$ & $43(26-68)$ & $59(27-88)$ \\
\hline eGFR decline rate $\left(\mathrm{ml} / \mathrm{min} / 1.73 \mathrm{~m}^{2} /\right.$ year $)$ & $-1.1(-4.6$ to -1.8$)$ & $-1.2(-4.6$ to -1.6$)$ & $-1.0(-4.3$ to -2.0$)$ & $-0.25(-4.6$ to -3.43$)$ \\
\hline Male (\%) & $566(49.1)$ & $304(49.1)$ & $221(49.4)$ & $41(47.7)$ \\
\hline Age (years) & $35.4 \pm 12.0$ & $36.5 \pm 12.1$ & $34.3 \pm 11.9^{*}$ & $33.0 \pm 10.6^{*}$ \\
\hline Urinary protein $(\mathrm{g} / \mathrm{d})$ & $1.42(0.72-2.62)$ & $1.19(0.62-2.39)$ & $1.44(0.82-2.71)^{*}$ & $2.51(1.62-3.99)^{* *}$ \\
\hline eGFR (ml/min/1.73 m²) & $79.12(52.08-101.67)$ & $78.46(48.37-103.41)$ & $81.67(56.59-100.82)$ & $65.95(47.11-91.95)^{*}$ \\
\hline Hypertension (\%) & $381(33.1)$ & $217(35.1)$ & $134(30.0)$ & $30(34.9)$ \\
\hline $\mathrm{MAP}(\mathrm{mmHg})$ & $95.8 \pm 13.5$ & $96.2 \pm 13.3$ & $94.9 \pm 13.3$ & $97.6 \pm 16.2$ \\
\hline \multicolumn{5}{|l|}{ Oxford classification } \\
\hline M1 (\%) & 469/1089 (43.1) & 208/586 (35.5) & $217 / 425(51.1)^{* *}$ & $44 / 78(56.4)^{* *}$ \\
\hline E1 (\%) & 459/1089 (42.1) & $157 / 586(26.8)$ & $239 / 425(56.2)^{* *}$ & $63 / 78(80.8)^{* *}$ \\
\hline S1 $(\%)$ & $839 / 1089(77.0)$ & $422 / 586(72.0)$ & $363 / 425(85.4)^{* *}$ & $54 / 78(69.2)$ \\
\hline $\mathrm{T} 1+\mathrm{T} 2(\%)$ & $364 / 1089$ (33.4) & 195/586 (33.3) & $133 / 425(31.3)$ & $36 / 78(46.2)^{*}$ \\
\hline With immunosuppression (\%) & $566 / 1078(52.5)$ & 288/578 (49.8) & $210 / 416(50.5)$ & $68 / 84(81.0)^{* *}$ \\
\hline
\end{tabular}

ESRD end stage renal disease, eGFR estimated glomerular filtration rate, MAP mean arterial pressure

* $\mathrm{P}<0.05$ and ${ }^{*} \mathrm{P}<0.001$ compared to the $\mathrm{C} 0$ group 
$140.9 \pm 11.1$ months). The multivariable Cox regression model indicated that patients in the $\mathrm{C} 1 \mathrm{HR}=1.07,95 \%$ CI $0.71-1.63)$ and $C 2$ groups $(\mathrm{HR}=0.84,95 \% \mathrm{CI} 0.41-$ 1.73) did not have a higher risk of ESRD than patients in the $\mathrm{C} 0$ group. Similarly, patients in the $\mathrm{C} 1(\mathrm{HR}=1.01$, 95\% CI 0.69-1.48) and C2 groups $(\mathrm{HR}=0.77,95 \% \mathrm{CI}$ 0.40-1.50) did not have a higher risk of the secondary outcome than those in the $\mathrm{C} 0$ group after adjusting for age, gender, eGFR, MAP, MEST scores, and immunosuppression (Fig. 1, Table 2). Furthermore, patients in the $\mathrm{C} 0, \mathrm{C} 1$ and $\mathrm{C} 2$ groups had a similar eGFR decline rate $\left[-1.2(-4.6\right.$ to -1.6$) \mathrm{ml} / \mathrm{min} / 1.73 \mathrm{~m}^{2} /$ year, -1.0 $(-4.3$ to -2.0$) \mathrm{ml} / \mathrm{min} / 1.73 \mathrm{~m}^{2} /$ year and $-0.25(-4.6$ to -3.43 ) $\mathrm{ml} / \mathrm{min} / 1.73 \mathrm{~m}^{2} /$ year] (Table 1, Additional file 1: Table S2).

\section{Subgroup analyses for crescent formation and progression to ESRD}

All patients were subdivided into subgroups based on the main clinical characteristics or whether they were receiving immunosuppressive agents. In patients with nephrotic-range proteinuria, crescent formation was associated with an increased risk of the primary outcome $(\mathrm{HR}=2.54,95 \% \mathrm{CI} 1.14-5.66, \mathrm{P}=0.02)$ and secondary outcome $(\mathrm{HR}=2.61,95 \% \mathrm{CI} 1.18-5.80, \mathrm{P}=0.02)$ after adjusting for age, gender, eGFR, MAP, pathological

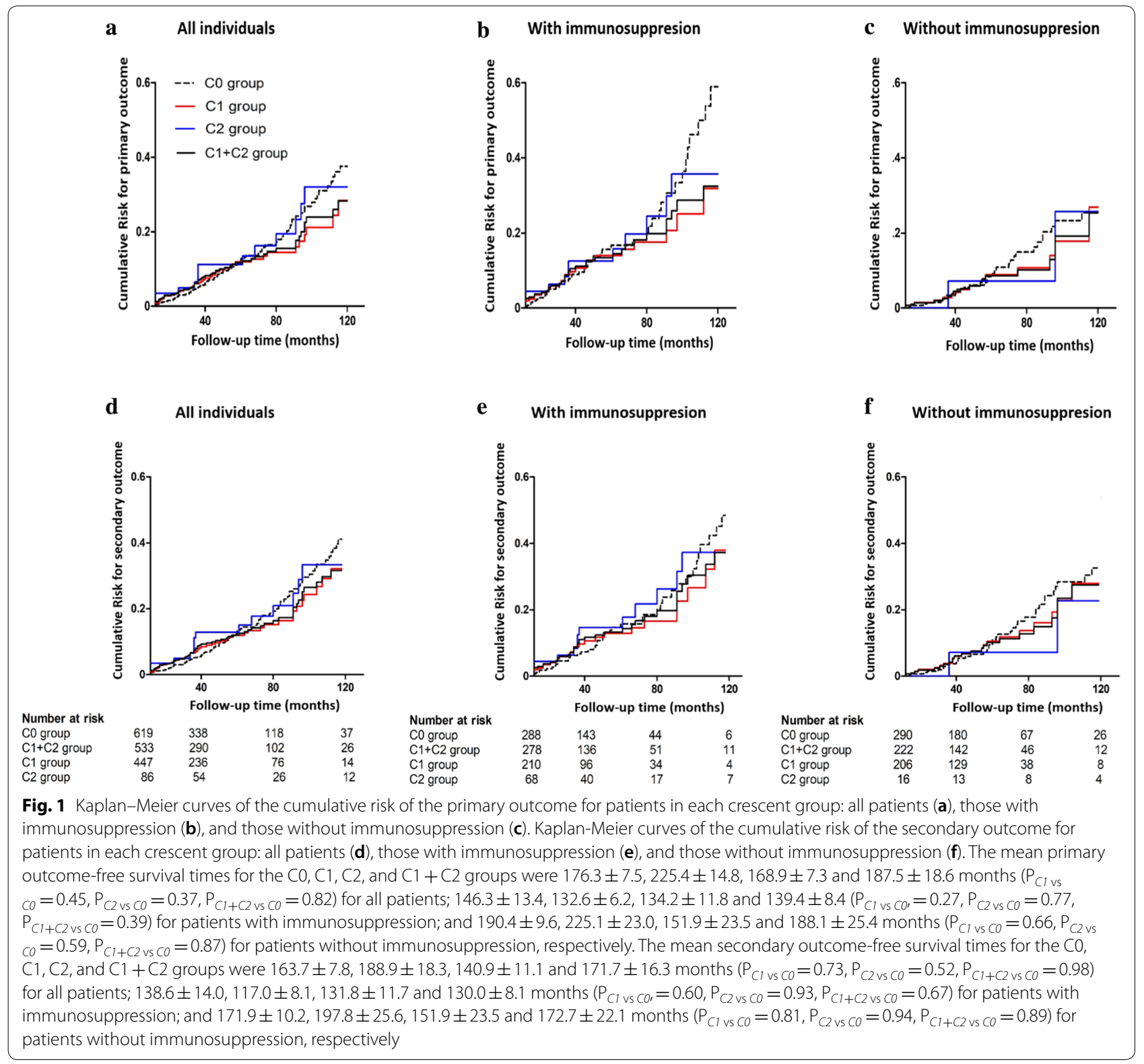


Table 2 Multivariate analysis of crescents with renal outcomes in IgAN patients with or without immunosuppression

\begin{tabular}{|c|c|c|c|c|c|c|c|}
\hline \multirow[t]{2}{*}{ Variable } & \multicolumn{3}{|c|}{ All patients } & \multicolumn{2}{|c|}{ With immunosuppression } & \multicolumn{2}{|c|}{ Without immunosuppression } \\
\hline & Events & HR $(95 \% \mathrm{Cl})$ & $P$ value & HR $(95 \% \mathrm{Cl})$ & $P$ value & $\mathrm{HR}(95 \% \mathrm{Cl})$ & $P$ value \\
\hline Primary outcome & $144(12.5)$ & & & & & & \\
\hline $\operatorname{CO}(n=619)$ & $80(12.9)$ & Reference & / & Reference & / & Reference & / \\
\hline$C 1(n=447)$ & $46(10.3)$ & $1.07(0.71-1.63)$ & 0.74 & $0.76(0.42-1.40)$ & 0.38 & $1.05(0.53-2.08)$ & 0.89 \\
\hline$C 2(n=86)$ & $18(20.9)$ & $0.84(0.41-1.73)$ & 0.63 & $1.09(0.41-2.86)$ & 0.87 & $0.48(0.12-1.91)$ & 0.30 \\
\hline$C 1+C 2(n=533)$ & $64(12.0)$ & $1.02(0.68-1.52)$ & 0.93 & $0.85(0.49-1.49)$ & 0.58 & $0.88(0.46-1.70)$ & 0.71 \\
\hline Secondary outcome & $162(14.1)$ & & & & & & \\
\hline $\mathrm{CO}(\mathrm{n}=619)$ & $89(14.4)$ & Reference & / & Reference & / & Reference & / \\
\hline C1 $(n=447)$ & $54(12.1)$ & $1.01(0.69-1.48)$ & 0.97 & $0.80(0.46-1.41)$ & 0.44 & $0.88(0.49-1.60)$ & 0.68 \\
\hline$C 2(n=86)$ & $19(22.1)$ & $0.77(0.40-1.50)$ & 0.44 & $1.16(0.49-2.73)$ & 0.74 & $0.32(0.09-1.21)$ & 0.09 \\
\hline$C 1+C 2(n=533)$ & $73(13.7)$ & $0.93(0.64-1.33)$ & 0.68 & $0.86(0.51-1.45)$ & 0.57 & $0.72(0.41-1.29)$ & 0.27 \\
\hline
\end{tabular}

HRs were adjusted for age, gender, initial eGFR, MAP, proteinuria, and Oxford classification indicators (including mesangial hypercellularity, endocapillary hypercellularity, segmental glomerulosclerosis and tubular atrophy/interstitial fibrosis)

indicators, and immunosuppression. No associations between crescent formation and the primary or secondary outcome were found in the other subgroups, including those based on age, gender, blood pressure, eGFR and immunosuppressive agents (Fig. 2).

\section{Discussion}

A recently study conducted by Haas and colleagues examined the presence of crescents in kidney tissue from IgAN patients and evaluated the effect of crescents on renal function progression [15]. In their multi-center retrospective cohort of 3096 IgAN patients [11-13, 17], crescents were found to be associated with an increased risk of renal outcomes (defined as a combination of ESRD and a 50\% eGFR decline), especially in patients not using immunosuppressive agents when $1 / 4$ was set as the cutoff for categorizing crescents. However, this finding must be validated in independent cohorts with diverse populations. In this study, we aimed to validate the association between crescents and IgAN progression in an extended Chinese cohort of IgAN patients who were followed for at least 1 year. Not surprisingly, we found that patients with crescents in kidney tissue had more severe clinical and pathological manifestations. However, we failed to validate crescents as an independent predictor of ESRD after adjusting for clinical and pathological variables in IgAN patients with or without immunosuppressive treatment, except in patients with nephrotic-range proteinuria.

Crescents are a common lesion identified by renal biopsy in IgAN patients and indicate severe glomerular injury. IgAN patients with crescentic glomerulonephritis (crescents in more than $50 \%$ of glomeruli) are recommended to undergo more aggressive treatment such as steroids or immunosuppressive agents according to the KDIGO guidelines [18]. However, the treatment strategy for IgAN patients with crescents in fewer than $50 \%$ of glomeruli is less clear, and the prognosis of these patients is uncertain since studies in this field have not reported consistent results [10, 19-24]. For example, neither the original Oxford study nor its largest validation study, the VALIGA study, found an association between crescents and the risk of renal function progression in IgAN patients $[12,17]$. In contrast, the presence of crescents conveyed a 2.3 -fold increased risk of renal failure in a meta-analysis that pooled 1487 IgAN patients from four Asian studies and one European study. The largest study in this field recruited 3096 patients from four large cohorts, including those in the original Oxford study and the VALIGA study. In this study, patients with any degree of crescents were included, and the associations between crescents and renal outcomes were evaluated by using $25 \%$ as the cut-off point of crescent formation, which was suggested by a previous study. However, we failed to replicate the association between crescent formation and renal outcomes, including the single outcome of ESRD and the combined outcome of a 50\% eGFR decline and ESRD. Possible explanations include the different formulas used by the studies to estimate eGFR. The study by Hass used the four-variable Modification of Diet in Renal Disease (MDRD) formula, whereas we used the CKD-EPI

(See figure on next page.)

Fig. 2 Stratified Cox regression models of the association of crescents with the primary outcome (a) and secondary outcome (b) in each subgroup. HRs were adjusted by initial eGFR, MAP, proteinuria, Oxford classification indicators (including mesangial hypercellularity, endocapillary hypercellularity, segmental glomerulosclerosis and tubular atrophy/interstitial fibrosis), and immunosuppressive therapy. UP urinary protein, eGFR estimated glomerular filtration rate 
$\mathbf{a}$

Age<35years $(n=612)$

Age $\geq 35$ years $(n=540)$

Male $(n=566)$

Female( $\mathbf{n = 5 8 6 )}$

$U P \geq 3.5 g / d(n=183)$

$U P \geq 1 \sim 3.5 \mathrm{~g} / \mathrm{d}(\mathrm{n}=538)$

$U P<1 g / d(n=431)$

With Hypertension $(\mathrm{n}=381)$

Without Hypertension $(n=771)$

eGFR $\geq 60 \mathrm{ml} / \mathrm{min} / 1.73 \mathrm{~m}^{2} \quad(\mathrm{n}=785)$

eGFR<60ml/min $/ 1.73 \mathrm{~m}^{2}(\mathrm{n}=367)$

With immunosuppression $(n=566$

Without immunosuppression $(n=512)$

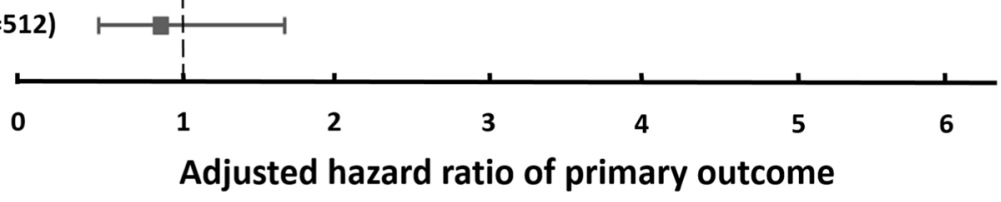

b

Age $<35$ years $(n=612)$

Age $\geq 35$ years $(n=540)$

Male $(n=566)$

Female(n=586)

$U P \geq 3.5 \mathrm{~g} / \mathrm{d}(\mathrm{n}=183)$

$U P \geq 1 \sim 3.5 \mathrm{~g} / \mathrm{d}(\mathrm{n}=538)$

$U P<1 g / d(n=431)$

With Hypertension $(n=381)$

Without Hypertension $(n=771)$

eGFR $\geq 60 \mathrm{ml} / \mathrm{min} / 1.73 \mathrm{~m}^{2} \quad(\mathrm{n}=785)$

eGFR<60ml/min $/ 1.73 \mathrm{~m}^{2}(\mathrm{n}=367)$

With immunosuppression $(n=566)$

Without immunosuppression $(n=512)$
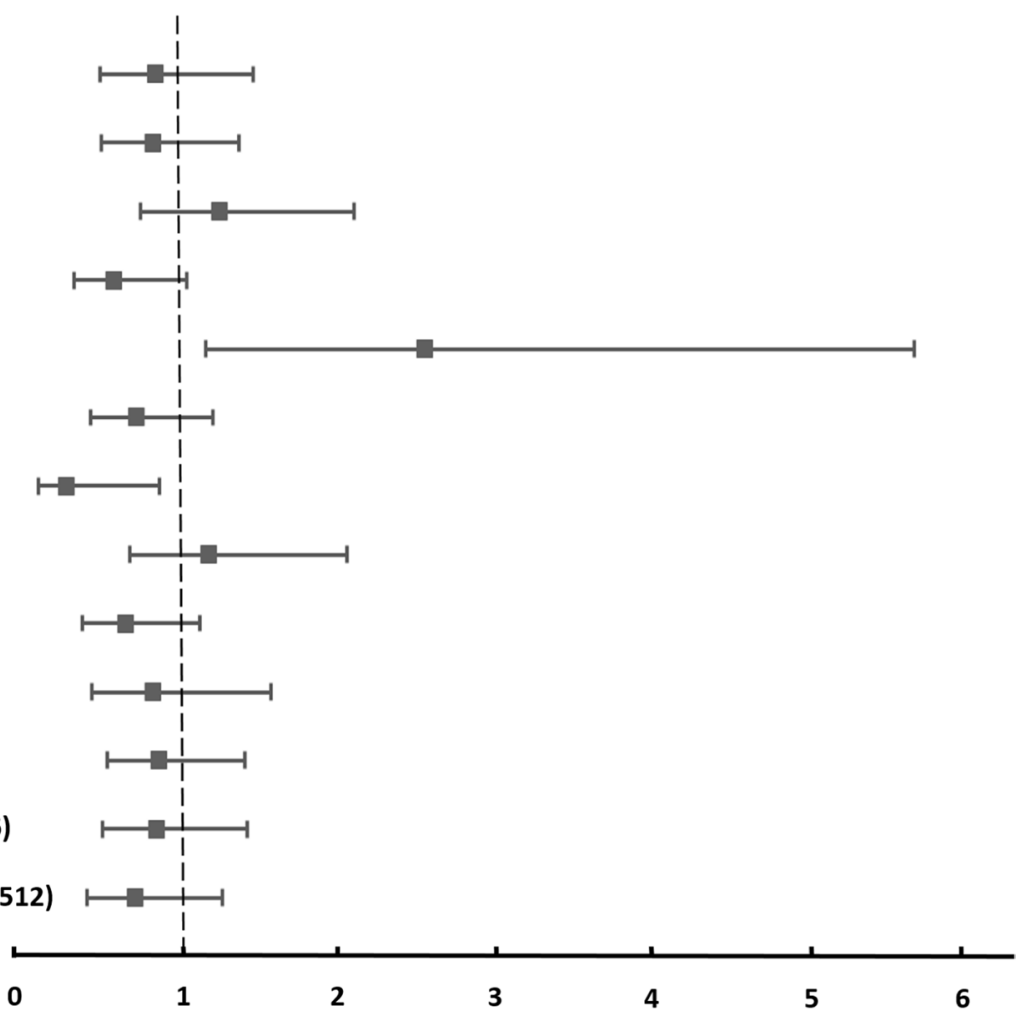

Adjusted hazard ratio of secondary outcome 
formula, which might be more accurate than the MDRD formula. Similar to our result, Lee et al. reported findings for 430 Korean IgAN patients after using the CKD-EPI formula to evaluate the prognostic value of crescents. Their results showed that crescents were not an independent prognostic factor by multivariable Cox analysis after adjusting for clinical factors and Oxford classification [25]. The different definitions of outcomes may also partially account for the discrepant findings. The study by Haas used a combined endpoint of a $50 \%$ decline in eGFR and ESRD, whereas other studies have used ESRD, which is a more robust outcome. However, considering the intrinsic nature of crescents, some IgAN patients with more crescents may present at an acute and early stage of renal damage. Consequently, the renal function decline in these patients may be reversible, even if the rate of eGFR decrease is more than $50 \%$. In this study, we failed to validate the increased risk of renal function progression in Chinese IgAN patients in the $\mathrm{C} 1$ or $\mathrm{C} 2$ groups compared to those in the $\mathrm{C} 0$ group by using different definitions of renal outcomes. In addition, we used a cut-off of one-sixth to increase the fraction of patients with crescents, and the results remained negative (Additional file 1: Table S1). Heterogeneity exists among the four cohorts included in the study by Haas [15]. Crescents were not associated with renal survival in the original Chinese study by $\mathrm{CH}$ Zeng et al. [13]. Furthermore, in the Japanese cohort including 702 IgAN patients, the predictive value of crescents was evident only in patients with initial proteinuria $<0.5 \mathrm{~g} /$ day and an eGFR $<30 \mathrm{ml} /$ $\mathrm{min} / 1.73 \mathrm{~m}^{2}$, whereas it was not seen in patients who met the inclusion criteria of the Oxford classification [11]. Thus, it is possible that crescents have better predictive value in severe cases of IgAN.

Although we were unable to replicate the association between crescents and ESRD in the whole cohort, subgroup analyses revealed that crescents were associated with a higher risk of ESRD in patients with nephroticrange proteinuria. Proteinuria $\geq 1 \mathrm{~g} /$ day has been identified as a risk factor for unfavorable prognosis in IgAN [26]. The above result indicated a synergistic effect between proteinuria and crescent formation. An earlier study found that widespread alterations in podocytes, including foot process effacement and prominent microvillous transformation, were observed in the process of crescent formation. Podocytes further initiated the proliferation of parietal epithelial cells to form cellular crescents by adhering to both the glomerular basement membrane and the parietal basement membrane [27, 28]. The evidence for podocytes being involved in the pathogenesis of crescent formation provides further clues regarding the association between crescent formation and the development of proteinuria.
There were limitations to this study. First, due to the retrospective study design, we could not evaluate crescent size, which possibly influences renal survival. Additionally, only 86 (7.5\%) patients were in the $\mathrm{C} 2$ group; this relatively low frequency of patients in the high crescent group might have decreased the statistical power in analyzing the clinical impact.

\section{Conclusions}

In this study, we found that IgAN patients with crescent formation had more severe clinical and pathological manifestations. However, we failed to replicate the association between crescents and renal function progression in Chinese IgAN patients with at least 1 year of follow-up.

\section{Additional file}

Additional file 1: Table S1. Adjusted HRs of the association of ESRD with crescents in more than $1 / 6$ of glomeruli. Table S2. Univariate analysis of crescents with eGFR decline rate $\left(\mathrm{ml} / \mathrm{min} / 1.73 \mathrm{~m}^{2} /\right.$ year).

\section{Abbreviations \\ IgAN: IgA nephropathy; ESRD: end stage renal disease; eGFR: estimated glo- merular filtration rate; MAP: mean arterial pressure; UP: urinary protein.}

\section{Authors' contributions}

$\mathrm{NC}$, JX and $\mathrm{HZ}$ designed the study. XZ, JX, NC, SS, YO, MY, and MS performed the data collection, statistical analysis, data interpretation, manuscript writing and manuscript revision. NC, JX, ZW, PS, HR and WW contributed to patient enrollment and follow-up. All authors read and approved the final manuscript.

\section{Author details}

${ }^{1}$ Department of Nephrology, Institute of Nephrology, Ruijin Hospital Affiliated with Shanghai Jiao Tong University School of Medicine, 197 Ruijin Er Road, Shanghai 200025, China. ${ }^{2}$ Renal Division, Peking University First Hospital, Institute of Nephrology, Key Laboratory of Renal Disease, Ministry of Health of China, Peking University, Beijing, China.

\section{Acknowledgements}

The authors thank all the staff of the Department of Nephrology and the nursing staff for their dedicated assistance in patient sample collection.

\section{Competing interests}

The authors declare that they have no competing interests.

\section{Availability of data and materials}

The datasets supporting the conclusions of this article are included within the article and its additional files.

\section{Consent for publication}

Not applicable.

\section{Ethics approval and consent to participate}

This study adhered to the principles of the Declaration of Helsinki II and was approved by the Institutional Review Board of Ruijin Hospital [Clinical Trial Ethics Committee Approval (2012-38)], Shanghai Jiao Tong University School of Medicine. Written informed consent was obtained from all the study participants.

\section{Funding}

This work was supported by grants from the National Key Research and Development Program of China (2016YFC0904100), National Key Technology 
R\&D Program (2011BAl10B06 and 2013BAl09B14), National Natural Science Foundation of China (Nos. 81570598, 81370015, and 81000295), Science and Technology Innovation Action Plan of Shanghai Science and Technology Committee (No. 17441902200), Shanghai Municipal Education Commission Gaofeng Clinical Medicine Grant (No. 20152207) and Shanghai Jiao Tong University School of Medicine Multi-Center Clinical Research Project (No. DLY201510)

\section{Publisher's Note}

Springer Nature remains neutral with regard to jurisdictional claims in published maps and institutional affiliations.

Received: 29 November 2017 Accepted: 18 April 2018

Published online: 03 May 2018

\section{References}

1. Xie J, Chen N. Primary glomerulonephritis in mainland China: an overview. Contrib Nephrol. 2013;181:1-11.

2. Levy M, Berger J. Worldwide perspective of IgA nephropathy. Am J Kidney Dis. 1988:12:340-7.

3. Xie J, Kiryluk K, Wang W, Wang Z, Guo S, Shen P, Ren H, Pan X, Chen X, Zhang W, et al. Predicting progression of IgA nephropathy: new clinical progression risk score. PLoS ONE. 2012;7:e38904.

4. Yang M, Xie J, Ouyang Y, Zhang X, Shi M, Li X, Wang Z, Shen P, Ren H, Zhang $W$, et al. ABO blood type is associated with renal outcomes in patients with IgA nephropathy. Oncotarget. 2017;8:73603-12.

5. Ouyang Y, Xie J, Yang M, Zhang X, Ren H, Wang W, Chen N. Underweight is an independent risk factor for renal function deterioration in patients with IgA nephropathy. PLoS ONE. 2016;11:e0162044.

6. Xie J, Lv J, Wang W, Li G, Liu Z, Chen H, Xu F, Sun J, Ouyang Y, Zhang X, et al. Kidney Failure Risk Prediction equations in IgA nephropathy: a multicenter risk assessment study in chinese patients. Am J Kidney Dis. 2018. https://doi.org/10.1053/j.ajkd.2018.01.043

7. Edstrom Halling S, Soderberg MP, Berg UB. Predictors of outcome in paediatric IgA nephropathy with regard to clinical and histopathological variables (Oxford classification). Nephrol Dial Transplant. 2012;27:715-22.

8. Haas M. Histologic subclassification of IgA nephropathy: a clinicopathologic study of 244 cases. Am J Kidney Dis. 1997;29:829-42.

9. Shi SF, Wang SX, Jiang L, LV JC, Liu LJ, Chen YQ, Zhu SN, Liu G, Zou WZ, Zhang $\mathrm{H}$, Wang HY. Pathologic predictors of renal outcome and therapeutic efficacy in IgA nephropathy: validation of the oxford classification. Clin J Am Soc Nephrol. 2011;6:2175-84.

10. Walsh M, Sar A, Lee D, Yilmaz S, Benediktsson H, Manns B, Hemmelgarn B. Histopathologic features aid in predicting risk for progression of IgA nephropathy. Clin J Am Soc Nephrol. 2010;5:425-30.

11. Katafuchi R, Ninomiya T, Nagata M, Mitsuiki K, Hirakata H. Validation study of oxford classification of IgA nephropathy: the significance of extracapillary proliferation. Clin J Am Soc Nephrol. 2011;6:2806-13.

12. Cattran DC, Coppo R, Cook HT, Feehally J, Roberts IS, Troyanov S, Alpers CE, Amore A, Barratt J, Berthoux F, et al. The Oxford classification of IgA nephropathy: rationale, clinicopathological correlations, and classification. Kidney Int. 2009;76:534-45.

13. Zeng CH, Le W, Ni Z, Zhang M, Miao L, Luo P, Wang R, Lv Z, Chen J, Tian J, et al. A multicenter application and evaluation of the oxford classification of IgA nephropathy in adult chinese patients. Am J Kidney Dis. 2012;60:812-20.

14. Working Group of the International Ig ANN, the Renal Pathology S, Roberts IS, Cook HT, Troyanov S, Alpers CE, Amore A, Barratt J, Berthoux F, Bonsib S, et al. The Oxford classification of IgA nephropathy: pathology definitions, correlations, and reproducibility. Kidney Int. 2009;76:546-56.

15. Haas M, Verhave JC, Liu ZH, Alpers CE, Barratt J, Becker JU, Cattran D, Cook HT, Coppo R, Feehally J, et al. A multicenter study of the predictive value of crescents in IgA nephropathy. J Am Soc Nephrol. 2017;28:691-701.

16. Levey AS, Stevens LA, Schmid CH, Zhang YL, Castro AF 3rd, Feldman HI, Kusek JW, Eggers P, Van Lente F, Greene T, et al. A new equation to estimate glomerular filtration rate. Ann Intern Med. 2009;150:604-12.

17. Coppo R, Troyanov S, Bellur S, Cattran D, Cook HT, Feehally J, Roberts IS, Morando L, Camilla R, Tesar V, et al. Validation of the Oxford classification of IgA nephropathy in cohorts with different presentations and treatments. Kidney Int. 2014:86:828-36.

18. Radhakrishnan J, Cattran DC. The KDIGO practice guideline on glomerulonephritis: reading between the (guide)lines-application to the individual patient. Kidney Int. 2012;82:840-56

19. Abe T, Kida H, Yoshimura M, Yokoyama H, Koshino Y, Tomosugi N, Hattori N. Participation of extracapillary lesions (ECL) in progression of $\lg \mathrm{A}$ nephropathy. Clin Nephrol. 1986;25:37-41.

20. Tang Z, Wu Y, Wang QW, Yu YS, Hu WX, Yao XD, Chen HP, Liu ZH, Li LS. Idiopathic IgA nephropathy with diffuse crescent formation. Am J Nephrol. 2002:22:480-6.

21. Abuelo JG, Esparza AR, Matarese RA, Endreny RG, Carvalho JS, Allegra SR. Crescentic IgA nephropathy. Medicine. 1984;63:396-406.

22. Lv J, Shi S, Xu D, Zhang H, Troyanov S, Cattran DC, Wang H. Evaluation of the Oxford classification of IgA nephropathy: a systematic review and meta-analysis. Am J Kidney Dis. 2013;62:891-9.

23. Kaneko Y, Yoshita K, Kono E, Ito Y, Imai N, Yamamoto S, Goto S, Narita I. Extracapillary proliferation and arteriolar hyalinosis are associated with long-term kidney survival in IgA nephropathy. Clin Exp Nephrol. 2016;20:569-77.

24. Lv J, Yang Y, Zhang H, Chen W, Pan X, Guo Z, Wang C, Li S, Zhang J, Zhang $J$, et al. Prediction of outcomes in crescentic lgA nephropathy in a multicenter cohort study. J Am Soc Nephrol. 2013;24:2118-25.

25. Lee MJ, Kim SJ, Oh HJ, Ko Kl, Koo HM, Kim CH, Doh FM, Yoo TH, Kang SW, Choi $\mathrm{KH}$, et al. Clinical implication of crescentic lesions in immunoglobulin A nephropathy. Nephrol Dial Transpl. 2014;29:356-64.

26. Wang W, Chen N. Treatment of progressive IgA nephropathy: an update. Contrib Nephrol. 2013;181:75-83.

27. Bariety J, Bruneval P, Meyrier A, Mandet C, Hill G, Jacquot C. Podocyte involvement in human immune crescentic glomerulonephritis. Kidney Int. 2005:68:1109-19.

28. Le Hir M, Keller C, Eschmann V, Hahnel B, Hosser H, Kriz W. Podocyte bridges between the tuft and Bowman's capsule: an early event in experimental crescentic glomerulonephritis. J Am Soc Nephrol. $2001 ; 12: 2060-71$. 